\title{
ESTRATÉGIA COMO PRÁTICA: UM ESTUDO DAS PRÁTICAS DA AÇÃO ESTRATÉGICA NO CLUSTER DE LOJAS COMERCIAIS DA RUA DAS NOIVAS EM SÃO PAULO
}

\author{
STRATEGY AS PRACTICE: A STUDY OF THE PRACTICES OF STRATEGIC ACTION IN THE \\ RETAIL CLUSTER ON RUA DAS NOIVAS IN SÃO PAULO
}

\author{
Recebido em 22.01.2013. Aprovado em 04.10. 2013 \\ Avaliado pelo sistema double blind review \\ DOI:http://dx.doi.org/10.12712/rpca.v7i3.256
}

\begin{abstract}
Marcio Luiz Marietto
profmarcioluiz@uol.com.br

Programa de Mestrado em Administração das Faculdades Campo Limpo Paulista (FACCAMP) - Campo Limpo Paulista - SP - Brasil.
\end{abstract}

\section{Cida Sanches}

cidasanches@uol.com.br

Programa de Mestrado em Administração das Faculdades Campo Limpo Paulista (FACCAMP) - Campo Limpo Paulista - SP - Brasil.

\section{Resumo}

A Estratégia como Prática (S-as-P) coloca os estudos em Estratégia Organizacional sob uma nova perspectiva de se avaliar o fenômeno da atividade estratégica, agora, em uma visão sociológica de ontologia intersubjetiva que permeia os significados compartilhados pelos atores sociais nos diversos níveis da organização e entre as organizações. 0 objetivo deste estudo foi o de analisar como os atores sociais (proprietários-empreendedores, gerentes, vendedores e outros atores sociais) situados no Cluster de Lojas Comerciais da "Rua das Noivas" em São Paulo/Brasil interagem com o ambiente interno e externo para a formulação, implementação e execução das estratégias através da organização e entre as organizações, e como estas práticas socialmente imersas em um sistema de atividades, legitimadas ou não, influenciam a estrutura das unidades do cluster que, concomitantemente, os influencia e, assim, direciona-os para os resultados que promovem a durabilidade dinâmica e longitudinal das organizações deste Cluster. A pesquisa obedeceu aos pressupostos qualitativos de investigação etnográfica utilizandose a ferramenta de gravação velada e evidenciando-se as dificuldades da pesquisa em campo. Os resultados demonstraram que parece ser pertinente inferir que o Strategizing acontece nas interações entre os atores sociais pertencentes ao Cluster e seus contextos institucionais de regras e recursos que restringem e ao mesmo tempo possibilitam a adaptação estrutural em multinível destes indivíduos, organizações e entidades presentes no Cluster na busca da legitimidade de suas atividades vinculadas à adaptação dinâmica de suas capacidades de compartilhamento de significados na consecução diária do Strategizing imerso no ambiente técnico-institucional dos rituais, cerimoniais e simbolismos da Instituição do Casamento.

Palavras-chave: Estratégia como prática. Etnografia. Strategizin. Significados compartilhados. Cluster de lojas comerciais.

\begin{abstract}
Strategy as Practice (S-as-P) sets studies in Organizational Strategy in a new perspective. This perspective assesses strategic activity in a sociological view of intersubjective ontology that permeates
\end{abstract}


the meanings shared by social actors between organizational levels and organizations. The aim of this study was to examine how the individuals (owners, entrepreneurs, managers, salespeople and other social actors) in the commercial store cluster on Rua das Noivas in Sao Paulo/Brazil interact with the internal and external environment in order to make, influence and execute strategies through and between organizations and how these practices, which are socially embedded in a system of activities, whether legitimated or not, influence the structure of the cluster units that concomitantly influence and lead to the outcomes that promote the dynamic and longitudinal durability of the organizations in this cluster. The study was conducted in compliance with the qualitative assumptions of ethnographic research using the tool of covert recording highlighting the difficulties of research in the field. As results we can infer that Strategizing appears to occur in the interactions between the social actors in the cluster and its institutional context of rules and resources and the same time these constrain and enable the structural and multilevel adaptation of these actors as they seek legitimacy for their activities involve the dynamic adaptation of their ability to share meanings in the daily achievement of Strategizing embedded in the institutional dynamic context of the rituals, ceremonies and symbolism of the Institution of Marriage.

Keywords: Strategy as practice. Ethnography. Strategizing. Shared meanings. Store clustering.

\section{Introdução}

Para Gimenez et alli (1999, p.62), a literatura sobre estratégia em pequenas empresas é altamente influenciada por duas grandes abordagens: uma de natureza econômica e outra de natureza empreendedora. A perspectiva econômica tem sido predominante na área, especialmente até meados da década de oitenta. Por outro lado, uma tendência mais recente, a empreendedora, está surgindo com o reconhecimento da possível importância da influência do comportamento individual sobre o processo de formação e implantação de estratégia, ainda que os esforços de pesquisa no campo de administração estratégica em pequenas empresas se têm mostrado pouco conclusivos em muitos aspectos.

Assim, percebendo-se a importância Econômica e Social dos pequenos empreendimentos comerciais, especificamente os Clusters de Lojas Comerciais localizados em diversas cidades ao redor do mundo, torna-se de fundamental importância conhecer as Práticas Estratégicas que regem seus gestores, sejam eles os proprietários-empreendedores, gerentes, vendedores ou outros atores sociais responsáveis pela na consecução diária de seus negócios. Desta forma, o que se pretende neste estudo é oferecer uma nova perspectiva de se estudar a Estratégia em Clusters Competitivos de Lojas Comerciais, ou seja, a perspectiva da Strategy as Practice ( $S$-as- $P$ ).

A $S$-as-P figura como uma nova abordagem no campo da Estratégia Organizacional que investiga as práticas, práxis, praticantes e a profissão de estrategista nas organizações com uma visão sociológica "sociological eye" - (Whittington, 2007), notadamente diferente da visão econômica tradicional da estratégia. O surgimento e a expansão da Estratégia como Prática $(S$ - $a s-P)$ provem de uma demanda reprimida da necessidade de se observar os estudos em Estratégia "por outra perspectiva", uma vez que se percebe o declínio na contribuição de velhos conceitos e ferramentas de análise (Doz e Prahalad, 1991), que não explicam com profundidade a realidade dos procedimentos e resultados sociais dos atores envolvidos na estratégia operacionalizada diariamente nas organizações. Os velhos conceitos apenas "arranham" a realidade socialmente construída pela Estratégia nas organizações ao longo do tempo, com isto a necessidade do advento de uma Visão Social da Estratégia.

Para que S-as-P pudesse propor seu "turn" - (Whittington, 2002; Jarzabkowski, 2004) com o paradigma positivista da Estratégia Econômica tradicional, (transcendendo a uma posição epistemológica interpretativa e intersubjetiva que privilegia a análise das atividades práticas contextualizadas no cotidiano de trabalho dos atores sociais envolvidos nos procedimentos estratégicos das organizações em uma perspectiva longitudinal de análise), teve de incorporar em seu corpo analítico teorias de proximidade epistemológica que pudessem suportar suas intenções e 


\section{ESTRATÉGIA COMO PRÁTICA: UM ESTUdO DAS PRÁTICAS DA AÇÃO ESTRATÉGICA NO CLUSTER DE LOJAS COMERCIAIS DA RUA DAS NOIVAS EM SÃo PAULO}

interações de análise para o desenvolvimento coerente de suas estratégias e procedimentos de pesquisa no campo em expansão.

Neste contexto, a $S$-as- $P$, especificamente, a Teoria da Visão Baseada na Atividade (Activity-Based View - ABV) recorre aos pressupostos epistemológicos da Teoria Histórico-Cultural da Atividade, onde sua principal argumentação, apoiada em Engeström (1993 e 2002), recai sobre a atividade compartilhada que é direcionada diretamente a um resultado, onde esta atividade é também distribuída e coletiva, porque os diferentes atores colocam suas ações individuais dentro das atividades e resultados do sistema de atividade, assim os atores individuais associam-se com a comunidade na construção da atividade orientada para os resultados (JARZABKOWSKI, 2005, p.35).

De tal modo, percebe-se que a $S$-as- $P$ suporta-se sobre uma ontologia intersubjetiva da realidade, as Estratégias de Pesquisa, em geral, deitam-se sobre procedimentos qualitativos de pesquisa, assim, este estudo tem a intenção de, por meio de Estratégias Qualitativos de coleta e análise de dados, em especial a etnografia e a análise de dados etnográficos, fornecer uma perspectiva da atuação laboral e diária sobre a Prática da Estratégica dos atores sociais, gestores, sejam eles os proprietáriosempreendedores, gerentes, vendedores ou outros indivíduos nas lojas do Cluster Comercial da "Rua das Noivas" na Rua São Caetano em São Paulo/Brasil.

A partir destas considerações pretende-se analisar neste estudo, sob o arcabouço conceitual da Estratégia como Prática na perspectiva da Teoria da Visão Baseada na Atividade o problema a seguir: Como, de que forma, por quem, quando, onde e por que a prática da ação estratégica nas organizações situadas em clusters de lojas comerciais competitivas é formada e direcionada pelos atores sociais imersos em um sistema social de indivíduos internos e externos à organização interagindo em um ambiente técnico-institucional, organizados pela estrutura social da organização e seu ambiente externo e mediados pelo Strategizing buscam e atingem suas orientações e objetivos, por meio do compartilhamento de significados direcionado aos resultados, enquanto promovem a durabilidade dinâmica destas organizações?

\section{Estratégia como Prática $(S$-as-P)}

Preliminarmente, explica-se que os estudos em Estratégia Organizacional do ponto de vista social são, relativamente, modernos. Neste contexto, Whittington (1996, p.732) fala que as ciências sociais têm investigado a prática dos cientistas, contadores e arquitetos e que neste momento é a vez dos estrategistas, assim, o autor inaugura um novo campo de estudos na Estratégia Organizacional, A Estratégia como Prática (Strategy as Practice) ou ( $S$-as-P).

Em coincidência com a proposta deste trabalho, Whittington (2007, p.1577) utiliza-se do experimento do casamento para explicar o potencial do olhar sociológico sobre a Estratégia:

\footnotetext{
Por que a estratégia deve ser estudada como outra prática social qualquer? Vamos tomar o casamento (apesar do direito, jornalismo ou guerra também se ajustarem). Os Sociólogos estudam casamento de muitas maneiras. Para começar, o casamento pode ser tratado como uma instituição socialmente imersa, tendo diferentes formas em diferentes sociedades e períodos. Aqui o fascínio sociológico é com a compreensão dessas diferenças, suas causas e suas consequências sociais. Casamento também envolve muitas classes diferentes de atores: os parceiros do próprio casamento (masculino, feminino, heterossexuais, homossexuais e assim por diante), mas também atores auxiliares (membros da família, figuras religiosas, funcionários do Estado e toda uma indústria de prestadores de serviços de apoio) cada uma com papéis a desempenhar e interesses para avançar. Esses atores, suas conexões e suas desconexões são um rico alimento para os sociólogos. Casamentos também podem ser tratados como episódios particulares (cerimônias) com associação ás práticas e parafernálias (cerimônias arcaicas, discursos grandiosos, vestidos extravagantes e assim por diante). Cheios de significados e armadilhas escondidas, estes são irresistíveis para a ironia do sociólogo. Finalmente - aqui pelo menos - os sociólogos não estão preocupados com os problemas de desempenho: assim, os casamentos podem ser tomados como unidades mais ou menos
} 
duradouras, com entradas particulares (variação de compatibilidade entre os parceiros), processos (maneiras de resolver as diferenças) e resultados (crianças, bem-estar económico, felicidade ou outros).

Whittington (2007, p.1578) conclui que tal como está, a Estratégia é predominantemente estudada no último sentido do exemplo acima, onde, como nos casamentos, as Estratégias Organizacionais possuem inputs (recursos), processos (tomada de decisões, mudança, entre outros) e outputs (resultados) normalmente ligados ao desempenho financeiro, por outro lado a visão sociológica da estratégia encoraja a observar a Estratégia em todas as suas manifestações amplamente conectada e profundamente imersa nos contextos sociais organizacionais.

Definição 1 (Visão Social da Estratégia): Por Visão Social da Estratégia entende-se que nem sempre as organizações buscam somente objetivos econômicos, em diversas ocasiões, até mesmo para atingirse a solução do problema econômico, as organizações têm de lidar com questões sociais, inclusive levando-se em conta o ambiente social que as organizações estão inseridas (WHITTINGTON, 1996; WHITTINGTON, 2007; MARIETTO, SANCHES e MEIRELES, 2011).

Marietto, Sanches e Meireles (2011), também, evidenciam que a $S$-as-P fornece as categorias e os níveis de análise quando sugerem estudos sobre as Práxis (Practice), Practitioners, Práticas e a Profissão de Estrategista (ou seja, o trabalho, os trabalhadores, as ferramentas e os consultores, professores, pesquisadores e estudantes em estratégia) nas organizações com uma visão sociológica. Portanto, não se vai a campo analisar as categorias das Práticas Estratégicas somente com o arcabouço teórico da $S$-as- $P$. A disciplina roga outras teorias de ontologias convergentes à prática diária imersa na realidade organizacional sob seu "guarda-chuva" para captura do seu contexto.

Neste sentido, muitas vezes, tentar enquadrar pressupostos econômicos como processo, conteúdo ou resultado (para detalhes adequados sobre estes pressupostos observar Bulgacov et alli, 2007) pode, por vezes, gerar uma incoerência ontológica e distorcer conceitos que a disciplina de $S$-as- $P$ não procura tratar, pois a mesma propõe a análise em um sentido sociológico apelando a uma estrutura de significados compartilhados sob uma ontologia intersubjetiva e interpretativa de potenciais procurando-se em capturar a prática estratégica na potência, no momento em que ela ocorre, por meio do compartilhamento de significados entre os atores sociais em seus diversos níveis, assim, pressupostos econômicos, de uma realidade positiva tida como "dada" não se enquadram nesta perspectiva dinâmica, uma vez que existe a necessidade do olhar sobre o momento e o aspecto temporal deste e não uma análise sobre algo que está positivamente outorgado como um processo, conteúdo ou resultado.

Definição 2 (Intersubjetividade): Intersubjetividade se refere ao compartilhamento de significados atribuídos por atores individuais em cada situação social específica, garantindo uma objetividade localizada, porque é espaciotemporalmente delimitada possibilitando o estabelecimento de pontes significativas em relação aos conceitos de subjetivo e objetivo (MACHADO-DA-SILVA, FONSECA e CRUBELLATE, 2005).

Categoria Analítica 1 (Significados Compartilhados): Entendimento tácito que emerge quando os membros de um ou mais grupos interagem (SCHEIN, 1992, p.7).

Whittington (2006) explica que os Practitioners são os primeiros que fomentam movimentação estratégica, são aquelas pessoas que tem o trabalho de fazer, formar e executar a estratégia nas organizações. Estes atores não são somente os diretores ou os executivos seniores das organizações, mas, também, em nível menos elevado na hierarquia, aqueles que fazem parte do staff estratégico ligados ao planejamento ou aos negócios estratégicos. Gerentes médios que também estão engajados no trabalho estratégico, não somente pela implementação, mas pela organização da agenda nos processos top-down, pela seleção de propostas e pela filtragem de informações estratégicas através da organização. Proeminentemente encontram-se aqui, também, os consultores de grandes consultorias e, 


\section{ESTRATÉGIA COMO PRÁTICA: UM ESTUDO DAS PRÁTICAS DA AÇÃO ESTRATÉGICA NO CLUSTER DE LOJAS COMERCIAIS DA RUA DAS NOIVAS EM SÃO PAULO}

frequentemente, outros atores como agentes de bancos de investimentos, advogados empresariais e gurus das escolas de administração (WHITTINGTON, 2006, p.619).

Expandindo-se, aqui, o conceito de Practitioners acentua-se que nas organizações de complexidade menor, independente de sua área de atuação (comércio, indústria, prestação de serviços, organizações do terceiro setor, instituições governamentais, entre outras categorias organizacionais) devem-se incluir como Practitioners os proprietários, sócio-proprietários, empreendedores, gerentes em qualquer nível, vendedores e/ou qualquer outra categoria profissional vinculada ao negócio, independente de sua lógica econômica, que, como em organizações de alta complexidade, possuam, também, a função e a responsabilidade de fazer, formar e executar a estratégia nestas organizações.

Categoria Analítica 2 (Practitioners): Pessoas que tem o trabalho de fazer, formar e executar a estratégia nas organizações (WHITTINGTON, 1996 e 2006).

Correlacionado aos Practitioners, Whittington (2006) pontua a práxis (Practice) observando que é o trabalho real dos practitioners, ou seja, "todas as diversas atividades envolvidas na formulação deliberada e na implementação da estratégia. Neste sentido, a Practice Estratégica é o trabalho intraorganizacional para fazer e garantir a execução da estratégia" (JARZABKOWSKI e WHITTINGTON, 2008, p.282).

De acordo com Jarzabkowski et al. (2006), a Práxis (Practice) pode ser entendida como "um fluxo de atividades situado e socialmente definido que gera como consequências os direcionamentos e a sobrevivência da empresa". Porém, este trabalho é extremamente difuso e incerto, pois grande parte dele pode ser visto em uma extensão maior ou menor de sequências de episódios e estes episódios podem incluir reuniões, intervenção de consultores, apresentações, discussão de projetos ou, simplesmente, conversas formais e informais, portanto o domínio da práxis (practice) engloba a rotina e a não rotina, o formal e o informal e as atividades no centro e na periferia das organizações (WHITTINGTON, 2006, p.619).

É na práxis (practice) da estratégia que ocorre a manipulação da estratégia via habilidade dos Practitioners em conduzi-las através dos diversos níveis (multinível) da organização e por meio dos seus sistemas, episódios e rotinas às direções e objetivos que desejam atingir, porém como um trabalho incerto uma vez que não podem prever as reações dos demais atores (WHITTINGTON, 2006; JARZABKOWSKI e WHITTINGTON, 2008 JARZABKOWSKI, 2004).

Categoria Analítica 3 (Práxis - Practice): É a natureza situada e recorrente das atividades diárias englobando a rotina e a não rotina, o formal e o informal e as atividades, em multinível, no centro e na periferia das organizações que produzem consequências estruturais que são reforçadas ou mudam ao longo do tempo (ORLIKOWSKI, 2010; WHITTINGTON, 2006; JARZABKOWSKI, 2004).

O termo Prática (Practices) implica em um desempenho repetitivo com o objetivo de tornar-se recorrente, habitual ou rotineiro para ratificar ações particulares (JARZABKOWSKI, 2004, p.531).

Para Jarzabkowski et alli (2006), as práticas (practices) são "intrinsecamente conectadas ao fazer, na medida em que fornecem os recursos comportamentais, cognitivos, processuais, discursivos e físicos através dos quais os atores constroem sua atividade".

As práticas da estratégia referem-se às rotinas compartilhadas de comportamentos que incluem as tradições, as normas e os procedimentos de pensamentos, ação e uso de "coisas" (ferramentas) (WHITTINGTON, 2006, p.619).

A prática da estratégia ocorre em multinível (Klein et al. 1999). Em um nível a prática pode estar especificamente organizada, imersa nas rotinas, nos procedimentos operacionais e culturas (Nelson e Winter 1982; Martin 2002) que formam os modos locais de ação estratégica. (...) Mas a teoria da prática enfatiza o extra-organizacional também - as práticas derivam a partir de grandes campos e sistemas sociais na qual uma organização, em particular está imersa. (...) E, ainda, em nível maior, existem as práticas estratégicas de toda uma 
sociedade. Estas práticas sociais, por exemplo, normas de apropriação de escala, escopo e estrutura estratégica que diferem através das nações e do mundo (Fligstein 1990; Djelic 1998); tipos de discursos que informam e legitimam a maneira de fazer estratégia (Barry e Elmes 1997; Maguire et al. 2004); e técnicas de estratégia específicas, ao menos para a extensão do que eles venham a definir por rotinas de ação estratégica legitimas (WHITTINGTON, 2006, p.620).

As práticas estratégicas são as ferramentas sociais, simbólicas e materiais através do qual o trabalho estratégico é feito. Estas práticas incluem as ferramentas derivadas da atividade diária da estratégia como as Cinco Forças de Porter, modelos de decisão e sistemas de orçamento, artefatos materiais e tecnológicos e Power Point, entre outros (Jarzabkowski e Whittington, 2008, p.282). Em outras palavras, em uma visão social do fenômeno, por exemplo, uma reunião para a realização e operacionalização de umas das ferramentas administrativas, como GUT, S-TODA, SWOT ou até mesmo para a implementação das Estratégias da Organização, também, figura como um evento social no sentido de que a reunião é carregada de objetos e rituais simbólicos, inclusive, de poder e expertise entre os participantes perante os demais indivíduos da organização, não se restringindo o uso destas ferramentas somente ao caráter instrumental de aplicabilidade das mesmas.

Categoria Analítica 4 (Práticas Estratégicas - Practice): São as ferramentas sociais, simbólicas e materiais que ocorrem em multinível, intrinsecamente conectadas, que fornecem os recursos comportamentais, cognitivos, processuais, discursivos e físicos através dos quais os atores constroem suas atividades no trabalho diário da estratégia (JARZABKOWSKI, 2004; WHITTINGTON, 2006; JARZABKOWSKI et alli, 2006; JARZABKOWSKI e WHITTINGTON, 2008).

\title{
Estratégia como Prática e a Visão Baseada na Atividade (Activity-Based View - ABV)
}

Como dito anteriormente, a $S$-as- $P$ possui uma de suas vertentes sobre a Teoria da Visão Baseada na Atividade $(\mathrm{ABV})$ que recorre aos pressupostos epistemológicos da Teoria Histórico-Cultural da Atividade, onde sua principal argumentação, apoiada em Engeström (1993 e 2002), recai sobre a atividade compartilhada que é direcionada diretamente a um resultado, onde esta atividade é também distribuída e coletiva, porque os diferentes atores colocam suas ações individuais dentro das atividades e resultados do sistema de atividade, assim os atores individuais associam-se com a comunidade na construção da atividade orientada para os resultados (JARZABKOWSKI, 2005).

Para iniciar esta argumentação busca-se localizar as especificidades em que a Estratégia como Prática, na elaboração da Visão Baseada na Atividade, recorre aos fundamentos epistemológicos da Teoria Histórico-Cultural da Atividade.

Em um primeiro momento, Jarzabkowski (2003, p.24) ao confeccionar um artigo sobre um estudo empírico das práticas nas universidades inglesas, a luz da Estratégia como Prática, utiliza a Teoria da Atividade para explicar que:

\begin{abstract}
A Teoria da Atividade conceitualiza o desenvolvimento psicológico como um processo de interação social dentro de contextos culturais e históricos (Vygotsky, 1978). A interação fornece uma base interpretativa a partir do qual os indivíduos atribuem significado à suas próprias ações e a dos outros, assim são capazes de exercer a atividade compartilhada (Vygotsky, 1978; Wertsch, 1985). O compartilhamento de atividade é prática, na medida em que é realizado com um resultado em mente (Engeström, 2002). O contexto da atividade prática é definido como um sistema de atividade (Engeström, 1993). Uma organização pode ser considerada um sistema atividade que compreende três componentes principais, os atores, as estruturas sociais coletivas, e as atividades práticas que realizam (cf. Blackler).
\end{abstract}

Todavia, é em Jarzabkowski (2005, p.34-37) que a autora recorre a Teoria da Atividade informando que a estrutura em que se apoia é originada por esta teoria, mas que não é uma representação da mesma em sua integridade. Com isso a autora oferece uma breve explicação da teoria recorrendo a Engeström (1993 e 2002) e Blackler (1993 e 2000), que parecem fornecer a aplicação da Teoria da 
Atividade no campo da administração.

Definição 3 (Atividade): Fenômeno cognitivo que deriva de uma ação interpretativa particular promulgando "significância" em uma determinada situação posicionada em circunstâncias físicas e sociais (JARZABKOWSKI, 2005).

Sua principal argumentação, apoiada em Engeström (1993 e 2002) recai sobre a atividade compartilhada que é direcionada diretamente a um resultado, onde esta atividade é também distribuída e coletiva, porque os diferentes atores colocam suas ações individuais dentro das atividades e resultados do sistema de atividade, assim os atores individuais associam-se com a comunidade na construção da atividade orientada para os resultados, com isto ressalta-se que "a atividade é um conceito de longa duração, um fluxo de atividades ao longo do tempo" (JARZABKOWSKI, 2005, p.35).

A conceitualização da atividade dentro de um sistema de atividades capacita-nos a gerar uma visão interdependente, entendendo, como as ações de uma parte do sistema afetam as ações em outra parte com estas interdependências mediadas pela prática. (...) Algumas práticas são situadas, significando que elas refletem as propriedades institucionais de toda uma sociedade na qual elas estão imersas e, também, a interpretação local destas práticas como artefatos para a ação (JARZABKOWSKI, 2005, p.36).

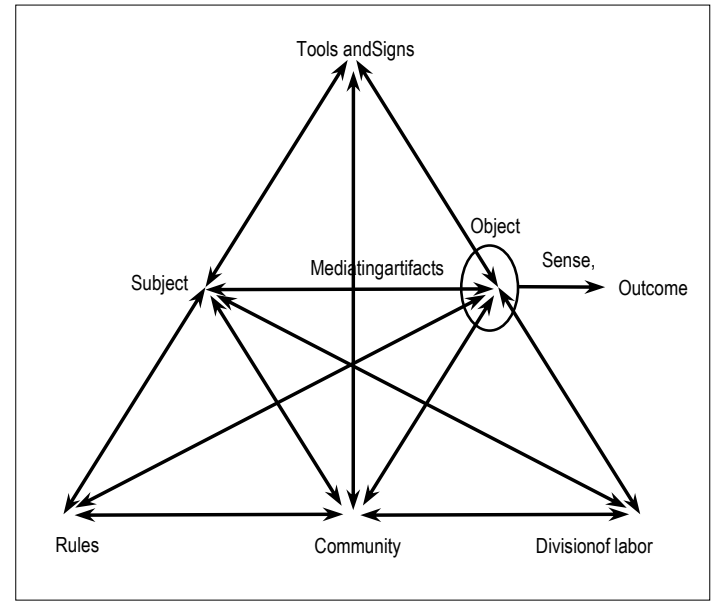

Figura 1: The structure of a human activity system. Fonte: Engeström (2001, p.135).

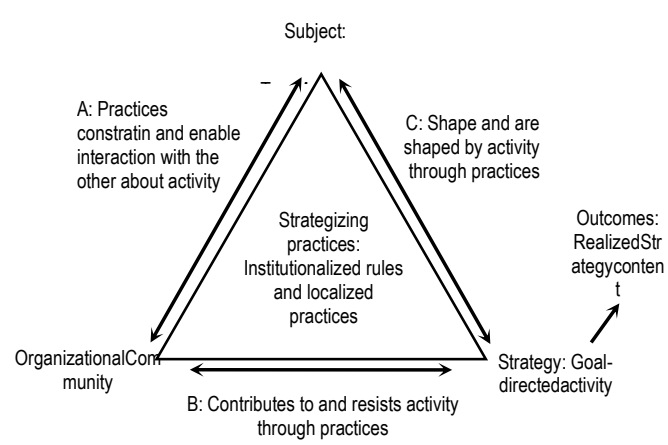

Figura 2: An activity theory framework for strategy as practice. Fonte: Jarzabkowski (2005, p.43).

Marietto, Sanches e Meireles (2011), ao analisarem o esquema apresentado na Figura 1, que significa a representação da Teoria da Atividade elaborada por Leontiev (1978) e Engeström (2001, p.134-135) demonstram o nível macro, do coletivo (a comunidade em que a atividade ocorre, com suas regras e divisão de trabalho), e o nível micro, do ator ou agente individual, operando com ferramentas e o subtriângulo superior pode ser visto como a "ponta do iceberg" representando ações individuais e de grupo imersas em um sistema de atividades coletivas. $O$ objeto é descrito com a ajuda de uma indicação oval, indicando que ações orientadas para o objeto são sempre explicita ou implicitamente, caracterizadas por ambigüidade, surpresa, interpretação, busca de sentido e potencial para mudanças.

A figura 2 é explicada por Jarzabkowski (2005, p.42) relacionando os Gerentes de Alto Escalão, Comunidade Organizacional e Estratégia com as Atividades Orientadas para os Resultados assumindo o Strategizing como mediador central da interação entre estes elementos. Deve-se observar que a gerência de alto escalão é o interesse da observação e a unidade de análise é o Strategizing, assim, os gerentes influenciam mutuamente as atividades orientadas para os resultados e a comunidade 
organizacional em função de sua posição na estrutura e acesso a recursos por meio da mediação das práticas do Strategizing (indicação das linhas internas). Logo, esta mediação limita e capacita as interações entre os gerentes e a comunidade organizacional (flecha A). Elas também mediam a contribuição e a resistência para a comunidade (flecha B) e fornecem veículos para os gerentes que estruturam e são estruturados pelas atividades por meio das práticas (flecha C). A dinâmica do sistema de atividade gera resultados que são chamados de Conteúdo da Estratégia Realizada da Organização (Marietto, Sanches e Meireles, 2011).

Destarte, percebe-se a origem do conceito de Strategizing que, em suma, possibilita entender a estratégia como o conjunto interações entre os atores sociais envolvidos nas atividades estratégicas e suas práticas que mediam as interações com o ambiente sobre a estratégia orientada para o resultado. Em outras palavras, estas práticas são as regras institucionalizadas na formação da estratégia e sua realização localmente situada como práticas administrativas e normas sociais.

Este Strategizing possui duas formas: a) uma forma processual que habilita o uso das práticas administrativas formais para moldar a adaptar a estratégia; e b) uma forma interativa que utiliza uma interação face-a-face na adaptação da estratégia possuindo um significado interpretativo da mediação da atividade estratégica que envolve as atividades gerenciais. Assim, o Strategizing confere diferentes dinâmicas de influencia no sistema de atividades para adaptar os padrões de atividades de diferentes maneiras (JARZABKOWSKI, 2005, p.59).

Categoria Analítica 5 (Strategizing): Conjunto de interações entre os atores sociais envolvidos nas atividades estratégicas e suas práticas, imersas em regras institucionalizadas na formação da estratégia e sua realização, localmente situada como práticas administrativas e normas sociais que mediam as interações com o ambiente sobre a estratégia orientada para o resultado (JARZABKOWSKI, 2005).

Finalmente, cabe ressaltar que o Strategizing ocorre imerso em um ambiente técnico-institucional. Machado-da-Silva e Fonseca (2010, p.40) definiram este ambiente de forma separada:

\begin{abstract}
Os ambientes técnicos, ou espaços de competição na ótica econômica, são aqueles cuja dinâmica de funcionamento desencadeia-se por meio da troca de bens ou serviços, de modo que as organizações que neles se incluem são avaliadas pelo processamento tecnicamente eficiente do trabalho. Logo, o controle ambiental é exercido sobre os resultados em termos de quantidade e qualidade, modelando as organizações através de um isomorfismo competitivo. Indústrias sujeitas a uma economia de mercado exemplificariam a força dos fatores técnicos (DiMaggio\& Powell, 1983; Scott \& Meyer, 1992). Os ambientes institucionais caracterizamse, por sua vez, pela elaboração e difusão de regras e procedimentos, que proporcionam às organizações legitimidade e suporte contextual. Nesse caso, o controle ambiental incide sobre a adequação da forma organizacional às pressões sociais, resultando em um isomorfismo institucional. Conforme mencionado anteriormente, sob condições de incerteza, as organizações sujeitam-se a requerimentos governamentais, copiam estruturas e práticas, ou implementam medidas genericamente aceitas em redes profissionais. Igrejas, escolas e hospitais públicos constituiriam alguns exemplos da influência dos fatores institucionais (DiMaggio\& Powell, 1983; Scott \& Meyer, 1992).
\end{abstract}

Machado-da-Silva e Fonseca (2010, p.40), ainda explicam que os ambientes técnicos e institucionais são facetas da mesma dimensão, ou seja, as demandas técnicas e econômicas ocorrem no ambiente técnico, logo as demandas sociais e culturais são postas pelo ambiente institucional. No entanto, podese expandir o conceito, na busca de caracterizar um ambiente técnico-institucional, inferindo-se que em um ambiente organizacional podem interagir, concomitantemente, em ambos os aspectos, sendo que no mesmo ambiente os elementos técnicos e econômicos interagem com os elementos sociais e culturais de forma intrínseca e, inclusive, possuem a propriedade de capacitar ou inibir a adaptação ao ambiente organizacional seja ele interno ou externo a organização.

Categoria Analítica 6 (Ambiente Técnico-Institucional): São aqueles cuja dinâmica de funcionamento econômica desencadeia-se por meio da troca de bens ou serviços, de modo que as organizações que neles se incluem são avaliadas pelo processamento tecnicamente eficiente do 


\title{
ESTRATÉGIA COMO PRÁTICA: UM ESTUdO DAS PRÁTICAS DA AÇÃO ESTRATÉGICA NO CLUSTER DE LOJAS COMERCIAIS DA RUA DAS NOIVAS EM SÃo PAULO
}

trabalho e pela elaboração e difusão de regras e procedimentos, que proporcionam às organizações legitimidade e suporte contextual (MACHADO-DA-SILVA e FONSECA, 2010).

\section{Clusters de Lojas Comerciais}

Para se fundamentar a caracterização de Clusters de Lojas Comercias inicia-se definido alguns conceitos de Clusters encontrados na literatura.

Porter (1998, p.78) definiu Cluster como:

\begin{abstract}
Concentrações de companhias e instituições interconectadas em um campo geográfico particular. Os clusters englobam uma matriz de indústrias e outras entidades interligadas importantes para a competição. Eles incluem, por exemplo, fornecedores especializados de matérias primas, maquinários e serviços e proveem uma infraestrutura especializada. Os clusters também frequentemente se estendem verticalmente para os canais e consumidores e lateralmente para os produtores de produtos complementares e as empresas relacionadas pelas habilidades, tecnologias, ou matéria-prima em comum. Finalmente, muitos clusters incluem instituições governamentais e outras como - universidades, agências reguladoras, usinas de ideias (thinktanks), empresas de treinamento vocacional e associações comerciais - que proveem treinamento especializado, educação, informação, pesquisa e suporte técnico.
\end{abstract}

Naturalmente, se percebe que a definição Porteriana de Cluster está voltada aos complexos industriais, objetos fundamentais de seus estudos investigativos sobre as relações econômicas e administrativas que se perfazem naquele campo.

Todavia, interessa aqui, as definições elencadas por Zaccarelli (2005). Em suas argumentações sobre Cluster o autor informa que este é representado por um conjunto de empresas que formam um conglomerado para competir com outras, não pertencentes ao Cluster ou para competir com outro Cluster. Neste sentido, o autor define Cluster como "agrupamento competitivo", esclarecendo que um cluster não é uma organização formalizada na qual as empresas "se inscrevem e ganham uma carteirinha de membro do cluster, como se fosse um clube ou associação", porém as empresas concentradas numa mesma área geográfica apresentam, naturalmente, um comportamento como um sistema, independente da sua consciência de participação no agrupamento (ZACCARELLI, 2005, p.197-198).

A principal contribuição de Zaccarelli (2005), para este estudo, está na sua menção de Clusters de Lojas Comerciais. Embora o autor não tenha definido claramente este conceito o mesmo deixa pistas para uma posterior definição.

Zaccarelli (2005, p.199) aborda algumas características competitivas destes clusters de lojas comercias exemplificando a possibilidade de se comprar peças de automóveis na Rua Duque de Caxias em São Paulo e não em lojas separadas apontando que as vantagens competitivas são a "disponibilidade de ampla linha de produtos e preços confiáveis", também enfatizando que estas vantagens competitivas surgiram independentemente da vontade dos lojistas, pois são "o resultado automático da concentração de lojas vizinhas resultando em vantagem sobre outras lojas isoladas geograficamente".

Deste modo, define-se:

Definição 4 (Clusters de Lojas Comerciais): Concentração de lojas comerciais e outras entidades comerciais e institucionais interconectadas em um campo geográfico particular, com a finalidade competitiva de vendas comerciais, seja em atacado e/ou varejo, de uma categoria de produtos específicos e similares, além de complementos, suplementos e seus componentes primários de produção (PORTER, 1998; ZACCARELLI, 2005). 


\title{
ESTRATÉGIA COMO PRÁTICA: UM ESTUDO DAS PRÁTICAS DA AÇÃO ESTRATÉGICA NO CLUSTER DE LOJAS COMERCIAIS DA RUA DAS NOIVAS EM SÃO PAULO
}

\section{Procedimentos de Coleta e Análise de Dados}

Procurando-se por uma definição consagrada de Etnografia, poder-se-ia arriscar dizer que "se trata de uma forma de investigação que recolhe dados com a preocupação de compreender a (i)racionalidade do outro, o outro cultural, o outro submisso, o outro iletrado, o outro não ocidental" (SHWEDER, 1997). No entanto, Maanen (1979, p.539) explica que a abordagem etnográfica é aquela da antropologia, e, em uma extensão mais limitada, da sociologia, figura sob o rótulo da observação participante. Como prática esta abordagem permite ao pesquisador de campo usar a cultura do ajuste/enquadramento "setting" (o conhecimento social adquirido e compartilhado disponível para os membros e participantes de um determinado grupo) para esclarecer os padrões observados da atividade humana.

$\mathrm{Na}$ Estratégia como Prática $(S$ - $a s-P)$ as abordagens etnográficas são atraentes e, normalmente, indicadas uma vez que se necessita de dados sobre os estrategistas e suas práticas dentro de um contexto espaço-tempo bem definido. Pode-se, também, observar que a Etnografia tem como premissa a observação close-up das rotinas que ocorrem naturalmente ao longo do espaço/tempo oferecendo novas dimensões de participação nos processos estratégicos e lançando um novo enfoque sobre esse tipo de trabalho: o Strategizing (MARIETTO, 2009; SAMRA-FREDERICKS, 2000a).

Debruçando-se sobre Samra-Fredericks (2000a e b), Whittington (2002) e Jarzabkowski e Wilson (2002), Marietto (2009) justifica a indicação do uso da Etnografia nos estudos de $S$-as- $P$ :

\begin{abstract}
Podemos perceber que a Etnografia, como estratégia de pesquisa para a Estratégia como Prática, possui fortes ligações como a visão ontológica e epistemológica, principalmente quando observamos o "turn" nos pressupostos ontológicos da Etnografia na direção da perspectiva intersubjetiva (Giddens, 1979 e 1984) para alcançar os significados da profissão, a prática, práxis e os practitioners que a constroem a estratégia nas organizações. Assim, a Etnografia é capaz de realizar observações do dia-a-dia do trabalho estratégico reforçando o rigor exigido no processo de pesquisa acadêmica.
\end{abstract}

Ademais, pode-se inferir que os procedimentos etnográficos pautados na observação participante e utilizados nas pesquisas organizacionais buscam captar o ambiente técnico e institucional do fenômeno em observação, assim, o como fazer a pesquisa etnográfica no campo organizacional tende a ensejar uma série de processos e instrumentos de coleta de dados tidos, talvez, como modernos a revelia dos cadernos, penas e lápis pitorescos utilizados por Malinowski ou Frans Boas, entre outros tantos antropólogos em seus apontamentos sobre suas observações, além dos mesmos terem de fazer uso excessivo de suas capacidades de memoria e memorização, pois os ambientes investigados tendem a ser dinâmicos e, muitas vezes, a mão que escreve tende a não acompanhar a velocidade dos acontecimentos forçando o pesquisador a fazer uso de sua memória na reconstrução dos fatos para suas anotações que, por vezes, poderia falhar e, devido a estes atenuantes, a Antropologia e a Etnografia foram colocadas em dúvida (Geertz, 1993) quanto ao rigor e veracidade dos fatos apurados nas décadas de 50 e 60 . Atualmente, de forma diferente do passado, o pesquisador pode se utilizar da Tecnologia da Informação como principal ferramenta para impor o rigor e veracidade dos dados coletados e, posteriormente, analisados.

Desta forma o pesquisador deve se valer de ferramentas primárias de pesquisas como gravadores em áudio e/ou vídeo, além da utilização de outras formas eletrônicas para as notas como laptops, notebooks, celulares, entre outros e, outros aparatos eletrônicos como ferramentas secundárias de pesquisa para a complementação das notas de campo, sendo instrumentos como videotapes, audiotapes, fotografias, além de documentos que podem ser coletados no campo como brochuras, reportagens, panfletos, arquivos, documentos institucionais, cartões de visita, reportagens, acesso a sites entre outros tantos, mas com a ênfase de que estes servem como complemento, pois a principal 
atenção recai sobre a interação pessoal do pesquisador com os indivíduos, grupo e contexto técnico institucional encontrado no ambiente de pesquisa.

Acerca do uso de gravações veladas (ou não declaradas) nos estudos organizacionais, especialmente na $S$-as- $P$, Samra-Fredericks (2000a, p.251) ilustra que:

\begin{abstract}
As gravações das interações produzem análises penetrantes de como as conversas dos atores sociais baseadas na prática sustentam as instituições sociais, bem como permite a análise de suas atividades intrincadas no sentido de demonstrar a complexidade destas situações. Para a produção de um estudo etnográfico completo devem-se realizar, também, entrevistas pautadas em conversas informais, onde e quando a oportunidade destas permitir, trabalhando na sombra (shadow) da observação não participante e recolhendo documentos empresariais sempre que possível. Deve-se reconhecer que muitas conversas importantes ocorrem fora das mesas de reuniões, nos corredores, nos estacionamentos, nos escritórios pessoais e, até mesmo, nos banheiros. O principal objetivo das gravações nos estudos etnográficos da $S$-as- $P$ é gravar as interações rotineiras das elites gerenciais e como elas acontecem, observando e trabalhando de maneira discreta (shadowing) para se obter um profundo entendimento da dinâmica comportamental para se compreender, primeiro, o que esta acontecendo, ao invés de martelar a teoria para dentro de um espaço disponível que o procedimento etnográfico pode oferecer.
\end{abstract}

Segundo Costa (2007, p.81), a análise dos dados se constitui em uma das fases mais complexas da pesquisa etnográfica, ressaltando-se que a interpretação do pesquisador acontece desde o momento de sua chegada física ao local e, inclusive, no momento das conversas, "afinal descrever uma situação vivência é uma forma de interpretar". Durante a permanência no local e os encontros novos significados foram atribuídos à experiência e reinterpretados no diálogo com o pesquisador, onde além de fazer perguntas tentou direcionar as conversas dos participantes até que a interpretação fosse possível ou que se tornasse evidente que o tema é compreendido de forma contextual aos pressupostos teóricos e as categorias analíticas que sustentam este trabalho.

Suporta-se, aqui, ainda que se derivando e expandindo-se em alguns termos, na proposta de Janesick (1995) descrita em Costa (2007, p.82-83) para a elaboração do Protocolo de Análise dos Dados Etnográficos: 1) Localizar na experiência relatada (filtrar), as frases ou afirmativas que se relacionam diretamente com o fenômeno estudado; 2) Interpretar o significado destas frases ou afirmativas como um leitor informado; 3) Obter a interpretação dos participantes, se possível; 4) Inspecionar os significados para verificar o que eles revelam sobre os aspectos essenciais e recorrentes ao fenômeno em concordância com as categorias analíticas; 5) Analisar as unidades de narrativas para verificar a frequência em que estas unidades são apresentadas nas falas e classifica-las segundo a proximidade de sentido das categorias analíticas evidenciadas no referencial teórico; 6) Realizar a triangulação, se possível, dos significados inspecionados entre os relatos dos diversos participantes e outros tipos de dados colhidos por outros meios que não as conversas para garantir a acurácia e rigor cientifico; 7) Elaborar prováveis inferências sobre o fenômeno com base nos aspectos e recorrentes identificados nas categorias analíticas para a contextualização teórico-empírica do estudo.

Desta forma, o Procedimento de Tratamento dos Dados envolveu a realização dos tópicos acima se apresentando excertos das transcrições das gravações realizadas em campo. Estes excertos foram contextualizados com as categorias analíticas apresentadas no referencial teórico.

Para o rigor e credibilidade desta pesquisa, os dados obtidos nas gravações foram transcritos em sua originalidade, inclusive transcrevendo-se possíveis erros de português, semântica ou concordância gramatical ocasionados no momento das conversas que aqui são adaptados na tradução para o idioma inglês. Do mesmo modo, ressalta-se que os possíveis erros previstos não são oriundos da qualidade ou falta de revisão deste trabalho, mas da fidelidade às transcrições das gravações.

Nota-se que, devido à restrição de espaço neste trabalho, os excertos aqui publicados são frações situacionais para contextualizar os resultados do total apurado. 


\section{Descrição do Campo de Pesquisa e Descrição do Procedimento Etnográfico de Coleta de Dados}

Fundada há 61 anos, a Rua São Caetano na cidade de São Paulo/ Brazil conta com 117 lojas de produtos de casamento, entre elas de vestido de noivas com cerca de 17 mil modelos prontos para aluguel e venda, além de trajes para damas de honra, madrinhas, padrinhos e noivos e itens de festa como lembranças, convites, fotos, vídeos, carros de aluguel entre outros. Mais de 50 estilistas especializados trabalham no local, que tem ainda três mil costureiras, 500 arrematadeiras e bordadeiras e 300 revendedoras, no entanto, estas últimas, estão espalhadas pelas fábricas responsáveis pelas confecções que não se encontram fisicamente na Rua São Caetano, mas distribuídas em outras regiões da cidade.

Segundo dados da Associação dos Lojistas da Rua São Caetano por lá circulam 34 mil pessoas todo mês incluindo-se pessoas de todo o Brasil, continente sul americano (Bolívia, Colômbia, Paraguai, Uruguai entre outros) e também africanos de países como Angola, Congo, entre outros que devido a proximidade geográfica e cultural com o Brasil optam por compras na cidade de São Paulo para abastecerem suas lojas nos respectivos países movimentando em torno de U\$2,0milhões/mês.

Foram efetuadas ao todo quatro visitas à Rua das Noivas em dias diferentes ao longo de 23 dias totalizando, em média, dez horas de permanência no local que resultaram, em média, em 6 horas de gravações.

Em um primeiro momento, o pesquisador esteve no local em um sábado, tradicionalmente o dia de maior movimento, sem quaisquer equipamentos eletrônicos primários ou secundários, acompanhado de sua atual namorada ("noiva" para os fins de abordagem) realizando investidas junto às lojas com o objetivo de realizar um reconhecimento primário (exploração do ambiente técnico-institucional) do local de pesquisa.

Adotou-se a estratégia em que o casal tinha a intenção de se casar em uma data futura e estava iniciando a pesquisa de preços e opções pelos aparatos cerimoniais e simbólicos pertinentes ao ritual do casamento. A noiva adentrava às lojas, como é de costume neste ritual na Rua das Noivas, uma vez que, em geral, o foco é dado à noiva, e ocupava-se em perguntar sobre diversas curiosidades contextuais ao ritual do casamento, enquanto que o noivo (o pesquisador) permanecia como ator de observação dos acontecimentos e aproveitando-se desta situação pode abstrair, por meio de observação e tomando notas escritas, as circunstâncias técnicas e institucionais que imperavam no ambiente.

Igualmente, acreditou-se que a receptividade ao pesquisador em momento futuro seria a mesma, ou seja, o pesquisador incorreu no viés de achar que, futuramente, ao se apresentar como pesquisador acadêmico com intenção de colher dados técnico-institucionais administrativos para a pesquisa sem nenhuma intenção de revelar dados que pudessem ser tidos como estratégicos para as lojas (faturamento, nomes de funcionários, proprietários ou clientes, procedimentos ou estratégias de concorrência, entre outros) o mesmo fosse acolhido da mesma forma, contudo, infelizmente, não foi isto que ocorreu no retorno do pesquisador ao campo (Rua das Noivas) 17 dias após a primeira vista. Observam-se um dos os excertos abaixo onde "P" refere-se ao pesquisador e "V" seqüencialmente, dentre seis lojas diferentes abordadas tanto de vestidos de noiva quanto de acessórios.

\footnotetext{
$P$ - Tudo bem? Deixa eu te fazer uma pergunta? Precisava conversar com o dono ou com o gerente aqui, estou fazendo uma pesquisa aqui na Rua das Noivas, eu queria fazer uma entrevista.

V1 - Então é assim, a gerente está com um cliente, e o dono mesmo ele não fica aqui, ele vem uma vez por semana só, só na segunda-feira de manhã.

$P$ - Se a Gerente puder já me ajuda.

$V 1$ - é que ela ta com cliente, tá meio corrido hoje
} 


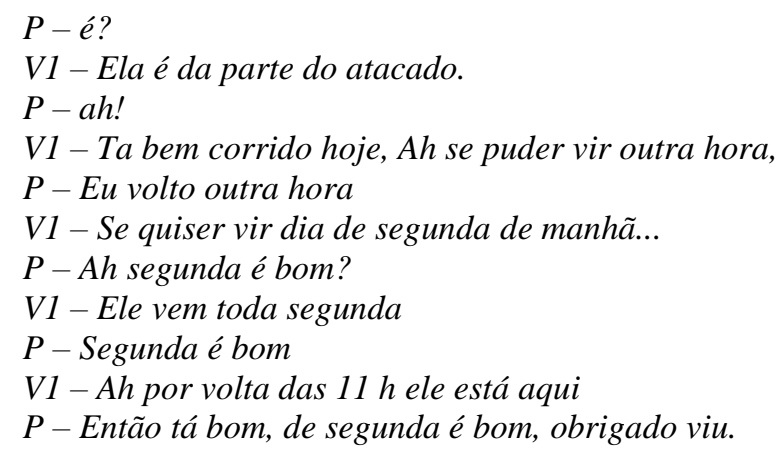

Percebendo-se as possibilidades de obstrução à intenção de coleta de dados para pesquisa, o pesquisador foi forçado a mudar sua forma e posicionamento pessoal para as investidas posteriores. A partir deste momento o pesquisador passou a atuar não mais na posição de pesquisador formal, mas agora como um cliente (noivo) que pretende se casar no futuro e está iniciando suas pesquisas sobre preços e possibilidades sobre os rituais do casamento, sendo que a partir deste momento, discretamente, abandonou a postura de pesquisador e passou a gravar de forma velada os diálogos surgidos. Finalmente, após o $3^{\circ}$ dia de vista a campo, o pesquisador passou a ser reconhecido com facilidade pelos indivíduos que trabalham no local levantando suspeitas sobre sua intencionalidade, inclusive, sendo questionado que a real intenção não era a de casar, mas que possuía ou tinha intenção de abrir uma loja no ramo de Noivas. A partir deste momento o pesquisador, tendo satisfeito seus propósitos de pesquisa e munido de dados etnográficos considerados suficientes para seus objetivos empíricos, encerrou as atividades em campo.

\section{Resultados}

Para as transcrições utilizar-se-á designativos conforme os abaixo na ordem exata em que os mesmos foram entrevistados ao longo dos dias, por exemplo, o primeiro vendedor(a) será designado "V1", o segundo vendedor(a) "V2" e, assim, sucessivamente em todas as categorias, em, sendo que as transcrições são distribuídas, também, por ordem de acontecimento:

"P" - Pesquisador;

"D" - Dono (proprietário) de loja;

"G" - Gerente;

"V" - Vendedor(a);

"R" - Recepcionista (puxador) - indivíduo incumbido de, nas calçadas da rua, influenciar o cliente, por meio de insistência, e entrar em determinada loja.

\section{A Conjuntura Sócio-Profissional na Rua das Noivas}

Dadas às características sobre a Rua das Noivas e percebendo-se os argumentos de Jarzabkowski (2005) para o Strategizing pode-se inferir que o Resultado das atividades estratégicas dos Practitioners na Rua das Noivas está direcionado às Vendas, ao Aluguel de alguns produtos, e, quando pertinente, a prestação de serviços relacionados aos rituais do Casamento. Ou seja, o resultado perseguido para a durabilidade dinâmica das Lojas neste Cluster é a venda, aluguel de seus produtos e prestação de serviços, mais do que outros fatores que poderiam se considerados se comparados a organizações mais complexas, onde muitas vezes só a venda não garante o resultado ou a sobrevivência da mesma, como fatores de negociação de fornecedores, inferências de órgãos governamentais, entre outros.

Ainda que este objetivo não tenha sido expressado de forma direta nas transcrições ficou evidente o posicionamento dos participantes a dedicação de suas atividades estratégicas e o conteúdo das conversas direcionando-se quase que exclusivamente para a venda e/ou aluguel dos produtos. Não se percebeu, nem foi evidenciado verbalmente, que as lojas ou os atores sociais instalados no Cluster 


\section{ESTRATÉGIA COMO PRÁTICA: UM ESTUdO DAS PRÁTICAS DA AÇÃO ESTRATÉGICA NO CLUSTER DE LOJAS COMERCIAIS DA RUA DAS NOIVAS EM SÃo PAULO}

possuíssem outras atividades para obter recursos financeiros que não fossem as vendas, aluguéis ou a prestação de serviços de acordo com sua expertise.

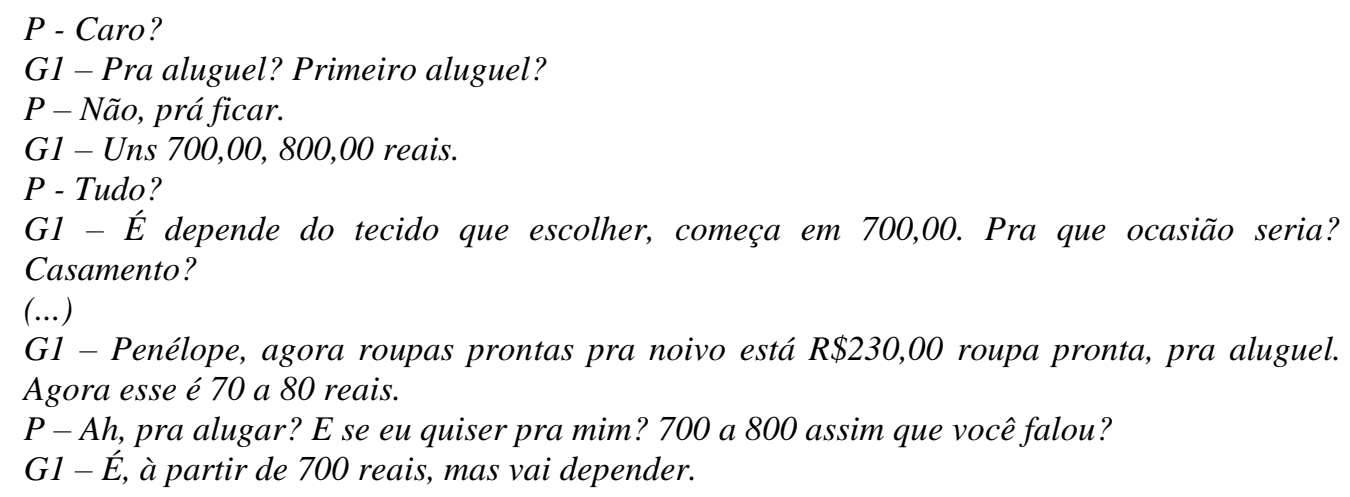

Em geral, no Cluster de Lojas na Rua das Noivas, percebe-se que os Practitioners (Whittington, 1996 e 2006) que realizam as atividades estratégicas são, basicamente, todos os atores sociais que participaram da pesquisa. Dadas as características das lojas serem, em sua maioria, constituídas como lojas comerciais e tratarem de um trabalho artesanal direto com o consumidor final os níveis hierárquicos observados são simples, consequentemente, os indivíduos que realizam o Strategizing diário nestas organizações são compostos pelos puxadores, vendedores, gerentes, estilistas e proprietários que se personificam como (Practitioners) atores sociais responsáveis pela condução das atividades estratégicas diárias nestas lojas.

Partindo-se do pressuposto que a venda e/ou o aluguel é o resultado perseguido pela atividade estratégica (Strategizing) dos Practitioners no Cluster apreende-se as características do Ambiente Técnico-Institucional (Machado-da-Silva e Fonseca, 2010) que estão imersos no contexto destas atividades.

O Ambiente Técnico-Institucional que está associado a este Cluster está imbricado aos rituais e cerimoniais simbólicos do casamento, inclusive, existem, também, rituais próprios internos às lojas na hora da compra ou aluguel dos vestidos onde, por exemplo, não é permitido o ingresso do noivo para não estragar a "surpresa", entre outras características de conduta das lojas que possuem como elemento principal a produção artesanal de seus componentes, ou seja, em geral tudo é feito de forma customizada e individual para cada cliente o que parece inferir os limites e as diretrizes a este ambiente técnico-institucional.

De fato, pode-se inferir que o conteúdo das Estratégias Econômicas e Sociais para durabilidade dinâmica destas organizações está calcado diretamente ao conteúdo Institucional dos rituais, cerimoniais e simbolismo da Instituição chamada Casamento. Em outras palavras, quanto mais legitimada esta a conduta do casamento perante a sociedade (eg: o casamento do Príncipe da Inglaterra) mais predizível e controlado é o Ambiente Técnico-Institucional auferido na Rua das Noivas garantindo, ainda que de forma indireta (eg: não se pode comprovar, nem foi objetivo deste estudo, que o casamento do Príncipe da Inglaterra aumente as vendas na Rua das Noivas), a durabilidade dinâmica das organizações pertencentes ao Cluster.

Outro ponto relevante a ser notado é a consciência da imersão no Ambiente Técnico-Institucional do Casamento pelos Practitioners. Os mesmos manifestam claramente sua consciência e percebem que a sobrevivência deles, bem como das lojas, esta diretamente vinculada à preservação destes rituais institucionais que estão presentes antes da existência dos mesmos e continuarão presentes após sua existência percebendo a validade cognitiva e o Compartilhamento de Significados (Schein, 1992, p.7) outorgados entre os mesmos e presentes em suas manifestações verbais de conhecimentos e vivência nestes rituais, além de se perceber a identificação destes indivíduos com as atividades relacionadas ao 
casamento, pelo tempo de atividade e a satisfação dos mesmos em atuarem neste ramo.

\begin{tabular}{|c|c|}
\hline $\begin{array}{l}\text { V8; V9 - A gente trabalha com sonho então a gente tem que dar } \\
\text { todas as informações do começo ao fim até a retirada, porque } \\
\text { elas são o cartão de visita, né? Então elas têm e ficam enviando } \\
\text { noiva pra loja, colegas, amigas. } \\
\text { (...) } \\
\text { V8; V9 - Ela entende tudo de casamento. A gente já viu de tudo } \\
\text { sobre casamento aqui. } \\
\text { P-Mas vocês vão no casamento também? } \\
\text { V8; V9-Maioria das vezes sim, algumas convida. } \\
\text { P-É mesmo, convida? } \\
\text { V8; V9-Mas não é sempre. } \\
\text { (...) } \\
P-\text { Mas como você tem essa percepção? } \\
\text { V8; V9 - Do atendimento, porque a gente trabalha com..., não é } \\
\text { só vender, eu particularmente, trabalho só..., né, eu trabalho } \\
\text { porque eu gosto mesmo, eu adoro trabalhar com noiva. Então a } \\
\text { gente fica feliz quando vê uma noiva casando feliz com o nosso } \\
\text { trabalho, tudo bem que o dinheiro é ... Tem muito mais valor ver } \\
\text { uma noiva casando feliz do que o nosso salário. }\end{array}$ & $\begin{array}{l}\text { D1 - Eu já to aqui há } 35 \text { anos. } \\
\text { P-Nossa.... (risos). } \\
\text { (...) } \\
\text { D1 - Olha competem. Mas é o } \\
\text { seguinte, é... que o ramo é uma coisa } \\
\text { meio artesanal mesmo. A indústria } \\
\text { corta um monte de calça e fica uma } \\
\text { coisa só, igual ao monte de japonês, } \\
\text { uma coisa só. Artesanal não, você } \\
\text { tem que falar, tem isso, tem isso; Tem } \\
\text { os estilistas na rua. }\end{array}$ \\
\hline
\end{tabular}

\section{O Sistema de atividades estratégicas na Rua das Noivas}

Estas atividades ou a Práxis (Practice) Estratégica (Orlikowski, 2010; Whittington, 2006; Jarzabkowski, 2004) manifestam-se de várias formas.

Ao evidenciarem-se as rotinas e não rotinas de vendas e atividades laborais diárias dos Practitioners localizados no Cluster notam-se o Strategizing acontecendo e possibilitando vasão aos elementos sociais que formam a estrutura de relações interpessoais dos contextos técnicos e institucionais permanentes ao Cluster de forma longitudinal.

Os rituais do casamento, enquanto cerimônia simbólica socialmente institucionalizada, balizam, possibilitam e ao mesmo estabelecem os limites dos procedimentos estratégicos de venda e/ou aluguel no Cluster e, consequentemente, a sua adaptação estrutural de relações sociais entre seus Practitioners.

A práxis (practice) isomórfica, entre as lojas (atividades coletivas orientadas para o resultado Jarzabkowski, 2010) é percebida em meio aos rituais de venda, locação e experimentação dos vestidos, bem como nos procedimentos padronizados de significação e comportamento destes Practitioners em meio aos outros atores sociais (como aos clientes, por exemplo) e a própria descrição hierárquica dos atores sociais que atuam nas atividades diárias (equipes) de vendas e/ou alugueis, bem como seus esquemas de recursos e regras organizacionais evidenciando-se suas formas de interação social em meio à hierarquia possibilitam a percepção do conteúdo isomórfico nestas rotinas diárias de Strategizing.

Em outro momento, esta práxis (practice) estratégica revela-se, agora, pelo lado dos proprietários de lojas. Ao se verificar que os proprietários possuem mais de uma loja no mesmo Cluster, pode-se inferir, também, um compartilhamento de significados destas práxis (practice) estratégicas devido, inclusive, à padronização dos produtos vendidos no Cluster. Ou seja, salvo as configurações artesanais customizadas pelos estilistas junto aos vestidos de noivas e alguns tipos e acessórios, em geral, os padrões isomórficos de práxis (practice) estratégicas, sejam pelos fornecedores, sejam pelos comportamentos e habilidades dos colaboradores, possibilitam-se aos proprietários adquirirem e manterem diversas lojas no cluster sem grandes modificações em seus ambientes técnicoinstitucionais. 


\section{ESTRATÉGIA COMO PRÁTICA: UM ESTUdO DAS PRÁTICAS DA AÇÃO ESTRATÉGICA NO CLUSTER DE LOJAS COMERCIAIS DA RUA DAS NOIVAS EM SÃO PAULO}

Outro ponto que, também, deixa claro esta práxis (practice) está na disponibilidade dos Practitioners em suas habilidades (observar nos excretos as habilidades e funções dos gerentes) para as atividades laborais para permanecerem no mesmo setor, ou seja, suas práxis (practice) encontram-se profundamente sedimentadas a ponto de ciar significados de "gostar do trabalho" e manterem-se por muitos anos no mesmo setor (como referido nos excertos anteriores) dando-se ênfase a suas redes de conexões profissionais e a proximidade de como estas práxis (practice) são semelhantes garantido o caráter isomórfico das mesmas e, assim, a manutenção estrutural do conteúdo social e profissional dos indivíduos que exercem suas atividades laborais, possibilitando a mudança de emprego sempre entre lojas do mesmo Cluster.

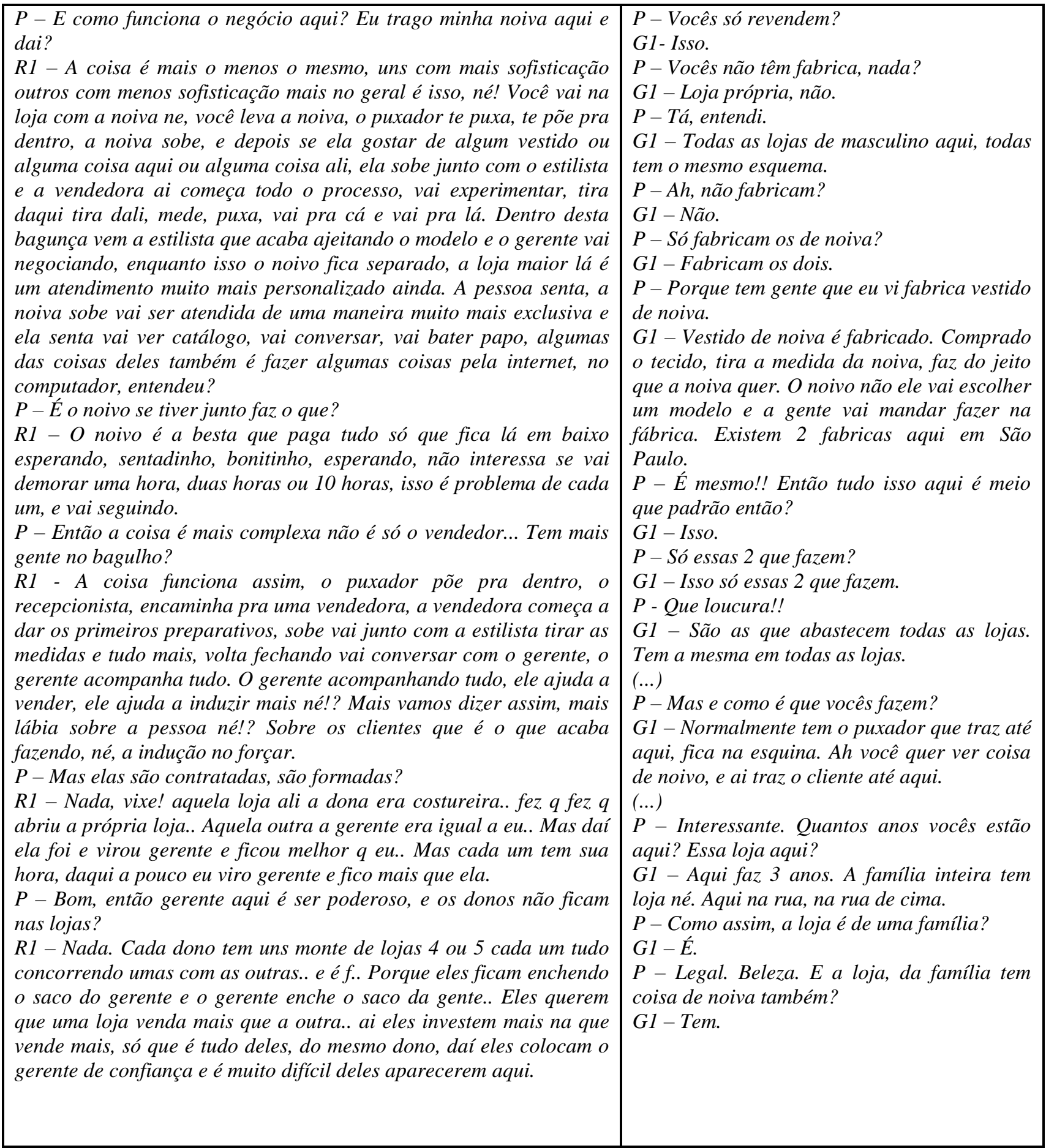


Tendo em vista o pressuposto teórico observado na figura 2 deste trabalho, ressalta-se que as Práticas Estratégicas (Jarzabkowski, 2004; Whittington, 2006; Jarzabkowski et al. 2006; Jarzabkowski e Whittington, 2008) são os mecanismos de mediação entre as pessoas e o mundo. Estes mecanismos podem ter a forma social, psíquica ou cognitiva e ainda operarem como instrumentos, procedimentos, rotinas e linguagens, onde a respeito de suas diferentes potencialidades, perspectivas e interesses os atores sociais integram suas ações em atividades compartilhadas na busca dos resultados que proporcionem a sobrevivência das organizações (JARZABKOWSKI, 2010).

Estas Práticas Estratégicas se mostram presentes de diversas formas na Rua das Noivas. O uso de ferramentas e serviços diferenciados, além da constante organização de eventos, workshops e outros procedimentos realizados de maneira singular por uma única loja ou interconectada entre as diversas lojas da rua e seus colaboradores, demonstram o compartilhamento de significados sobre o Strategizing presente nestes sistemas de atividades, evidenciando as Práticas Estratégicas como mecanismos de mediação com o mundo no sentido de acompanharem tendências e se integrarem (todo o cluster) para a busca do resultado em direção à sobrevivência das lojas pertencentes ao mesmo.

Seguindo a lógica de Whittington (2006), diversas ferramentas legítimas (tecnológicas ou não) são utilizadas, em nível de uma única loja, para se buscar certo diferencial social na direção de Práticas Estratégicas para a sobrevivência da organização, como, por exemplo, a organização de um workshop por uma loja ou a disponibilização de serviços customizados por outra loja do Cluster.

\begin{tabular}{|c|c|}
\hline 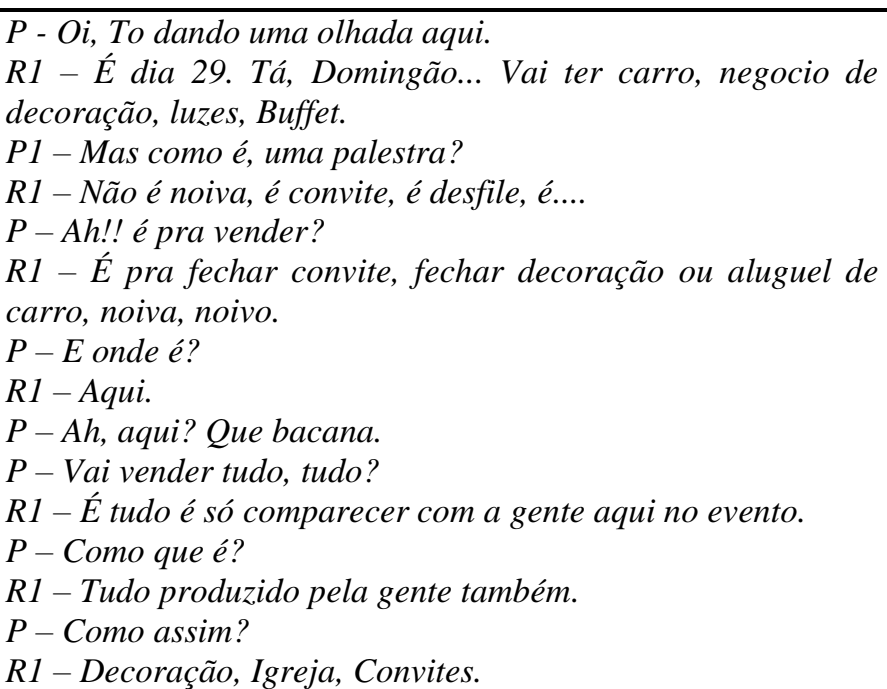 & $\begin{array}{l}\text { "É possível se comprar online na Rua } \\
\text { das Noivas, e algumas lojas dispõem do } \\
\text { serviço de motoboy de entregas para que } \\
\text { as noivas possam provas os vestidos com } \\
\text { mais tranquilidade em casa, podendo ser } \\
\text { trocados ou ajustados, caso necessário. } \\
\text { Há também lojas especializadas com } \\
\text { programas online de computador onde a } \\
\text { noiva pode "montar" seu próprio } \\
\text { vestido, descrever suas características } \\
\text { físicas, que em alguns dias o seu vestido } \\
\text { estará pronto para ser provado! Legal, } \\
\text { não? } \\
\text { www.vestidosnoiva.org Acessado em } \\
21 / 02 / 2011\end{array}$ \\
\hline
\end{tabular}

Por outro, inclinando-se para as Práticas Estratégicas nos grupos de lojas do Cluster, quando realizadas em conjunto e imersas em um contexto social compartilhado pelos grupos, estas atividades possuem o objetivo de mediar o sistema de atividades na qual a comunidade focal esta estrategicamente engajada. Este aspecto mediador tende a aumentar a coordenação e os sentidos das atividades compartilhadas na busca do resultado, ainda que individual para cada loja, mas com a legitimidade compartilhada pelo ambiente técnico-institucional de todo o Cluster.

Em outras palavras, as lojas pertencentes ao Cluster ao se organizarem em conjunto, estrategicamente, para compartilhar rituais e procedimentos, como exposições ou eventos, demonstram a interconexão institucional de suas atividades estratégicas na busca de aumento nos resultados de vendas e/ou alugueis de seus produtos permeando a sobrevivência destas organizações e, respectivamente, promovem suas interações com o ambiente social externo que as influenciam e ao mesmo tempo é influenciado por elas. Ademais, trechos retirados de reportagens sobre as Práticas Estratégicas utilizadas na Rua das Noivas em atividades organizadas entre os diferentes atores sociais em diferentes níveis (indivíduos, grupos ou lojas) que compartilham tradições, normas e os 


\title{
ESTRATÉGIA COMO PRÁTICA: UM ESTUdO DAS PRÁTICAS DA AÇÃO ESTRATÉGICA NO CLUSTER DE LOJAS COMERCIAIS DA RUA DAS NOIVAS EM SÃo PAULO
}

procedimentos de pensamentos, ação e uso de "coisas" (ferramentas - Whittington, 2006) com o objetivo de buscar o resultado que proporciona a durabilidade dinâmica das lojas que compõem o Cluster.

\begin{abstract}
"O prefeito Gilberto Kassab abrirá a II Mostra Rua São Caetano de Produtos para Casamento, no sábado, dia 24, às 12h30, em uma tenda indiana, onde acontecerá um desfile de 15 noivas com trajes daquele país, fornecidos por MukeshChandra, proprietário das lojas Ganesh. O empresário também entregará ao prefeito uma estátua de Ganesh, Deus da Prosperidade. Mas as comemorações de abertura não pararam por aí. Kassab receberá das mãos dos lojistas da rua uma tela da artista plástica Sonia Menna Barreto, única a ter uma obra na Royal Colection, coleção particular da rainha Elizabeth, da Inglaterra, e um buquê com 455 flores, nas cores da bandeira do município. $O$ evento termina neste domingo e reúne mais de 150 expositores, espalhados pelos 430 metros da rua: empresas especializadas em fotos, buffets, viagens, acessórios, vídeo, telão, músicos e DJs; salões; sítios; aluguel de carros; trajes para noivos, pais, pajens e padrinhos; vestidos para as damas de honra; bemcasados e lembrancinhas; arranjos de flores; buquês naturais e artificiais; aluguel de móveis; agências de viagens; jóias e semi-jóias; coroas, garras e arranjos de cabelo; cabeleireiros; Dia da Noiva e sapatos; entre outros".
\end{abstract}

www.destaquesp.com Acessado em 19/05/2011

\section{Considerações finais}

O fenômeno da Estratégia foi observado, aqui, através das lentes conceituais da $S$-as- $P$, em uma perspectiva ontológica intersubjetiva e com pressupostos sociológicos que nortearam a base teórica deste estudo, e deixou claro como a Estratégia, enquanto objeto/fenômeno de análise em nível de estudos organizacionais, pôde ser observada por outra perspectiva que não a Positivista Econômica.

Observou-se, também, que a $S$-as- $P$, bem como a etnografia, são fontes poderosas para se analisar fenômenos sócio/organizacionais que ocorrem entre níveis (multilevel), dentro e entre as organizações (nesta pesquisa micro e meso level). Constatação diferente de muitas criticas sobre a incapacidade da $S$-as-P de analisar observar além do micro level.

Pode-se perceber, por meio da análise dos dados empíricos, como acontece a dinâmica das atividades diárias da estratégia, quem são os atores sociais e em que momentos estas atividades estratégicas alinham os elementos de busca pelos resultados e, consequentemente, a sobrevivência das lojas imersas em um ambiente técnico-institucional, com as características institucionais do fenômeno social denominado Casamento que impõem influência indireta sobre os significados compartilhados nas atividades estratégicas no Cluster de Lojas Comerciais da Rua das Noivas em São Paulo.

Em outras palavras, uma constatação que parece ser interessante de ser avaliada está em como a legitimidade temporal dos rituais e cerimoniais simbólicos da Instituição do Casamento influencia o Strategizing e a sobrevivência dos atores sociais que trabalham nas lojas, as próprias lojas e o Cluster como um todo, em multinível, por meio da imersão social de seus Practitioners em sistema de atividades, relativamente isomórfico, na adaptação e integração econômica e social das lojas na atividade laboral diária dentro do Cluster.

Parece ser pertinente perceber que as habilidades, práticas, procedimentos, ferramentas, conversas formais e informais, rituais de abordagens e vendas, workshops, eventos, revistas, reportagens, entre outros elementos observados, emergem das interações entre os atores sociais pertencentes ao Cluster e seus contextos institucionais de regras e recursos que restringem e ao mesmo tempo possibilitam à adaptação estrutural em multinível dos atores sociais, organizações e entidades presentes no cluster na busca da legitimidade de suas atividades estratégicas focadas no resultado e, assim, possibilitando a durabilidade dinâmica destas organizações.

Algumas sugestões para pesquisa futuras deitam-se na possibilidade de se pesquisar a Prática Estratégica dos atores sociais em outros tipos de Clusters de Lojas Comerciais, em outras localidades 
geográficas como, por exemplo, o Cluster de produção e venda de flores as margens dos canais em Amsterdã na Holanda, entre outros tantos, além do aprofundamento da $S$ - $a s$ - $P$ em outras categorias de organizações sobre a lógica de Pequenas e Médias Empresas.

As possibilidades teórico-analíticas seguem-se sobre as derivações dos pressupostos da $S$-as- $P$, como por exemplo, o Estruturacionismo, além das diferentes perspectivas nas Estratégias e Métodos de Pesquisa Qualitativos direcionados a $S$-as- $P$ e seus elementos de análise.

\section{Referências}

BLACKLER, F. Organizing process in complex activity networks. Organization, n.7, 2000.

BLACKLER, F. Knowledge and theory of organization: Organizations as activity Systems and the reframing of management. Journal of Management Studies, 1993.

BULGACOV, S. SOUZA, Q. R. PROHMANN, J. I. P. COSER, C. BARANIUK, J. Administração estratégica: teoria e prática. São Paulo: Atlas, 2007.

COSTA, G. M. C. Deixar de ser mulher: conhecimento e significado cultural da menopausa. Tese de Doutorado. Escola de Enfermagem da Universidade de São Paulo. São Paulo: USP, 2007.

DOZ, Y. L. PRAHALAD, C. K. Managing DMNCs: A search for a new paradigm. Strategic Management Journal, v.12, 1991.

ENGESTRÖM, Y. Non scholae sed vitae discimus: como superar a encapsulação da aprendizagem escolar. In: DANIELS, H. (org.). Uma introdução a Vygotsky. São Paulo: Loyola, p. 175-197. 2002.

ENGESTRÖM, Y. Expansive Learning at Work: toward an activity theoretical reconceptualization. Journal of Education and Work, v.14, n.1, 2001.

ENGESTRÖM, Y. Developmental Studies of Work as a Test bench of Activity Theory: The case of primary care medical practice. In: Understanding Practice. Cambridge University Press, 1993.

GEERTZ, C. The Interpretation of Cultures. London: Fontana Press, 1993.

GIMENEZ, F. A. P. PELISSON, C. KRÜGER, E. G. S. HAYASHI JR, P. Estratégia em Pequenas Empresas: uma Aplicação do Modelo de Miles e Snow. RAC, v.3, n.2, 1999.

JANESICK, V. J. The dance of qualitative research design. Metaphor, methodolatry, and meaning. In: DENZIN N. K. LINCOLN, Y. S. Handbook of qualitative research. Thousands Oaks: Sage; 1994. p. 209-219.

JARZABKOWSKI, P. An activity-theory approach to Strategy as Practice. In: GOLSORKHI, D. ROULEAU, L. SEIDL, D. VAARA, E. Cambridge Handbook of Strategy-as-Practice. UK: Cambridge University Press, 2010.

JARZABKOWSKI, P. Strategy as Practice: An Activity-Based Approach. London: SAGE Publications, 2005.

JARZABKOWSKI, P. Strategy as Practice: Recursiveness, Adaptation, and Practices-in-Use. Organization Studies, v.25, n.4. London: SAGE Publications, 2004.

JARZABKOWSKI, P Strategic practices: an activity theory perspective on continuity and change. Journal of Management Studies, 2003.

JARZABKOWSKI, P. BALOGUN, J. SEIDL, D. Five key questions and a conceptual framework for strategy-as-practice research. EGOS Conference, 2006.

JARZABKOWSKI, P. WHITTINGTON, R. A Strategy-as-Practice Approach to Strategy Research and Education. Journal of Management Inquiry, v.17 n.4, p.282-286, 2008. 


\section{ESTRATÉGIA COMO PRÁTICA: UM ESTUdO DAS PRÁTICAS DA AÇÃO ESTRATÉGICA NO CLUSTER DE LOJAS COMERCIAIS DA RUA DAS NOIVAS EM SÃO PAULO}

JARZABKOWSKI, P. WILSON, D. Top Teams and Strategy in a UK University. Journal of Management Studies, v.39, n.3, 2002. p.355-381.

LEONTIEV, A. Activity, Consciousness, and Personality. Englewood Cliffs, Prentice-Hall, 1978.

MAANEN, J. V. The fact of fiction in organizational ethnography. Administrative Science Quarterly, v.24, 1979.

MACHADO-DA-SILVA, C. L. FONSECA, V. S. Competitividade organizacional: uma tentativa de reconstrução analítica. RAC, Edição Especial, 2010. p.33-49.

MACHADO-DA-SILVA, C. L. FONSECA, V. S. CRUBELLATE, J. M. Estrutura, agência e interpretação: elementos para uma abordagem recursiva do processo de institucionalização. RAC, 1a. Edição Especial, 2005. p.09-39.

MARIETTO, M. L. Ontological and Epistemological Assumptions for Ethnography in S-as-P Studies. In: Annals of 2009 Academy of Management Process Research Methods Workshop. Chicago: Academy of Management, 2009.

MARIETTO, M. L. SANCHES, C. MEIRELES, M. Strategy as Practice: a discussion of the epistemological appropriation of historical-cultural activity theory by the activity-based view toward an ontology of practice of strategy in organizations. In: Annals of 2011 Annual Meeting of the Academy of Management. San Antonio, Texas: Academy of Management, 2011.

ORLIKOWSKI, W. J. Practice in research: phenomenon, perspective and philosophy. In: GOLSORKHI, D. ROULEAU, L. SEIDL, D. VAARA, E. Cambridge Handbook of Strategy-asPractice. UK: Cambridge University Press, 2010.

PORTER, M. E. Clusters and the new economics of competition. Harvard Business Review, 1998.

SAMRA-FREDERICKS, D. Doing Boards-in-Action Research: an ethnographic approach for the capture and analysis of directors and senior managers interactive routines. Corporate Governance, An International Review, v.8, n.3, 2000a.

SAMRA-EREDERICKS, D. An analysis of the behavioral dynamics of corporate governance - $a$ talk-based ethnography of a UK manufacturing board-in-action. Corporate Governance, An International Review, v.8, n.4, 2000b.

SCHEIN, E. H. Organizational culture and leadership. San Francisco: Jossey-Bass, 1992.

SHWEDER, R. A. A rebelião romântica da antropologia contra o iluminismo, ou de como há mais coisas no pensamento para além da razão e da evidência. Educação, Sociedade \& Culturas, n.8, 1997.

WHITTINGTON, R. Strategy Practice and Strategy Process: Family Differences and the Sociological Eye. Organization Studies, v.28, 2007.

WHITTINGTON, R. Completing the Practice Turn in Strategy Research. Organization Studies. London: SAGE Publications, 2006.

WHITTINGTON, R. Practice Perspectives on Strategy: Unifying and Developing a Field. Best Paper Proceedings. Denver: Academy of Management, 2002.

WHITTINGTON, R. Strategy as practice. Long Range Planning: v.29, n.5, p.731-735, 1996.

ZACCARELLI, S. B. Estratégia e sucesso nas empresas. São Paulo: Saraiva, 2005. 